\title{
Effect of the Addition of Carbon on the Sintering Properties of Boron Carbide Ceramics prepared by Pressureless Sintering
}

\author{
Xiumei Shi ${ }^{1,2 a^{*}}$, Jianwu Cao ${ }^{2 b}$, Zhipeng $\mathrm{Li}^{2 \mathrm{c}}$, Dongming Yan ${ }^{2 \mathrm{~d}}$ \\ 1,2a* Northwestern Polytechnical University, Xi'an ,710072 China sxm4083@163.com \\ Ningbo Branch of China Academy of Ordnance Science, Ningbo,315103 China \\ ${ }^{2 b}$ Ningbo Branch of China Academy of Ordnance Science, Ningbo,315103 China, \\ ylswebken@163.com \\ ${ }^{2 c}$ Ningbo Branch of China Academy of Ordnance Science, Ningbo,315103 China, \\ 18753582169@163.com \\ ${ }^{2 d}$ Ningbo Branch of China Academy of Ordnance Science, Ningbo,315103 China, \\ Yandongming5278@sina.com
}

Keywords: Boron carbide; Pressureless Sintering; Carbon; Densification.

Abstract. Effect of the addition of carbon on the sintering properties of pressureless sintered boron carbide ceramics was investigated by using carbon black and phenolic resins as the main additives. There were three ways for adding Carbon, carbon black adding, phenolic resins adding and adding carbon black and phenolic resins mixtures. The density and microstructure of sintered $\mathrm{B}_{4} \mathrm{C}$ ceramics were analyzed by densitometer and optical microscope respectively. The effect on the densification of $\mathrm{B}_{4} \mathrm{C}$ ceramics by different content and adding method of carbon were analyzed and summarized. The results showed that the $\mathrm{B}_{4} \mathrm{C}$ ceramics has the optimum properties, that bulk density, bending strength, hardness and fracture toughness achieve $2.42 \mathrm{~g} / \mathrm{cm}^{3}, 335 \mathrm{MPa}, 22 \mathrm{Gpa}$ and $3.17 \mathrm{Mpa} \cdot \mathrm{m}^{1 / 2}$, respectively under the adding the mixture of $5.5 \%$, carbon black and $1.5 \%$, phenolic resins.

\section{Introduction}

$\mathrm{B}_{4} \mathrm{C}$ materials have been widely used in the fields of nuclear power industry, bombproof armour, military and other high-tech industries due to its excellent physical and chemical properties. $\mathrm{B}_{4} \mathrm{C}$ materials have low density very super hardness, high elasticity modulus, good neutron absorption ability and high chemistry stability. However, it is difficult to achieve high sintered density of boron carbide $\left(\mathrm{B}_{4} \mathrm{C}\right)$ ceramics because of the very strong B-C covalent bond,low plasticity, high resistance to gain boundary sliding $[1,2]$. In addition, the presence of $\mathrm{B}_{2} \mathrm{O}_{3}$ on $\mathrm{B}_{4} \mathrm{C}$ surface slows down the densification process. It is also difficult to reduce porosity due to the grain boundary and materials diffusion needs very high temperature. This work focus impact of Carbon for the properties of $\mathrm{B}_{4} \mathrm{C}$ by $\mathrm{t}$ changing the composition of Carbon and also changing the different Carbon sources[3,4].

The results showed that the mixture of Carbon powder and phenolic resins effectively remove the oxide layer on top of the $\mathrm{B}_{4} \mathrm{C}$ surface, increase the surface energy of ceramic, both are in favor of densification of $\mathrm{B}_{4} \mathrm{C}$ ceramics by using carbon black and phenolic resins as the main additives[5,6]. The density and microstructure of sintered $\mathrm{B}_{4} \mathrm{C}$ ceramics were analyzed by densitometer and optical microscope in order to identify the optimum composition if mixture of black and phenolic resins.

\section{Experimental procedure}

\section{Materials}

Boron carbide powder that diameter is less than $0.5 \mu \mathrm{m}$ and its purity is more than $99.5 \%$ was used in the present investigation, the Fe inpurity inside Boron carbide is less than $0.8 \%$. Activate Carbon has specific surface area which is more than $260 \mathrm{~m}^{2} / \mathrm{g}$ and particle sizeis less than $15 \mathrm{~nm}$; phenolic resins which has around 50\% concentration; the active Carbon and phenolic resins were used as the main 
addition sintering aid. $\mathrm{Al}_{2} \mathrm{O}_{3}$ of $99.5 \%$ in purity were commercially available. Table 1 presents the compositions of studying system.

Table 1 Composition of sintering system,wt $\%$

\begin{tabular}{cccccccccccccc}
\hline $\begin{array}{c}\text { Materials/ratio } \\
\text { wt } \%\end{array}$ & 1 & 2 & 3 & 4 & 1 & 2 & 3 & 4 & 1 & 2 & 3 & 4 \\
\hline $\mathrm{B}_{4} \mathrm{C}$ & 96.1 & 95.1 & 94.1 & 93.1 & 99.1 & 98.6 & 98.1 & 97.6 & 95.6 & 94.1 & 92.6 & 91.1 \\
Carbon black & 3.5 & 4.5 & 5.5 & 6.5 & 0 & 0 & 0 & 0 & 3.5 & 4.5 & 5.5 & 6.5 \\
Phenolic resins & 0 & 0 & 0 & 0 & 0.5 & 1.0 & 1.5 & 2.0 & 0.5 & 1.0 & 1.5 & 2.0 \\
$\mathrm{Al}_{2} \mathrm{O}_{3}$ & 0.4 & 0.4 & 0.4 & 0.4 & 0.4 & 0.4 & 0.4 & 0.4 & 0.4 & 0.4 & 0.4 & 0.4 \\
\hline
\end{tabular}

\section{Procedure}

Boron carbide powders, $\mathrm{Al}_{2} \mathrm{O}_{3}$, carbon black, phenolic resins, with certain amount of deionized water and dispersant were grounded in a polyurethane pot for $5 \mathrm{~h}$. The dry composite powders were molded into certain size pellets under a pressure of about $150 \mathrm{Mpa}$ for 6 seconds. These compacts were sintered in a vacuum furnace with vacuum of $5 \times 10^{-2} \mathrm{~Pa}$ under Ar atmosphere, sintering temperature is $2280^{\circ} \mathrm{C}$.

\section{Results and discussions}

\section{Carbon black to the performance of $\mathrm{B}_{4} \mathrm{C}$}

The raw materials were selected according to the system- 1 of the Table 1. Carbon black was chosen as main sintering aids with the weight content(or mass content) of $3.5 \%, 4.5 \%, 5.5 \%, 6.5 \%$ and no phenolic resin were added. The density of boron carbide with varying addition of carbon black in the range of 3.5\%-6.5\% is shown in Fig. 1. Pellet sintered with 3.5\% of carbon black showed a density of $2.21 \mathrm{~g} / \mathrm{cm}^{3}$, which increased with the addition of carbon black. The highest density obtained with $5.5 \mathrm{wt} \%$ carbon black addition was $2.35 \mathrm{~g} / \mathrm{cm}^{3}$, and then the density went down with further more additive of carbon.

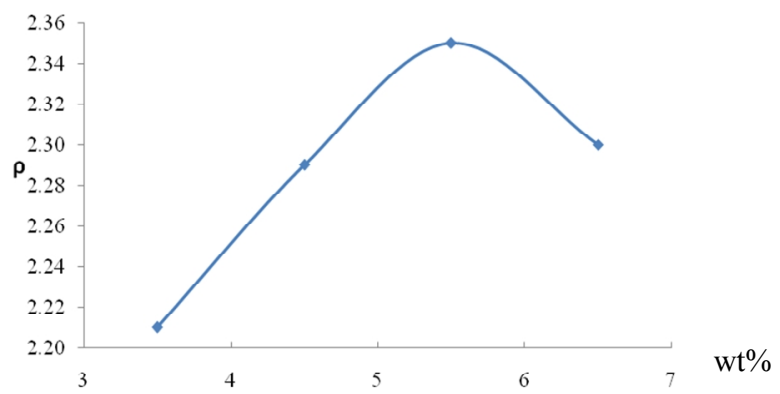

Fig1.the densities of $\mathrm{B}_{4} \mathrm{C}$ samples with different contents of carbon black

Microstructures of sintered boron carbide samples with carbon black additions are given in Fig.2. Fig.2(a and b) present the samples with 3.5\% and 4.5\% carbon black with more and uniformly distributed pores. Microstructures of $\mathrm{B}_{4} \mathrm{C}$ with $5.5 \%$ carbon black is shown in Fig. 2c, which both the number and the size of pores showed a downward trend. Fig. $2 \mathrm{~d}$ presents that the sample with $6.5 \%$ 
carbon black with bigger pores, and some of which are inter connected. However, the samples with carbon black addition as the only carbide source had high porosity, which decreased the sintered density of $\mathrm{B}_{4} \mathrm{C}$.

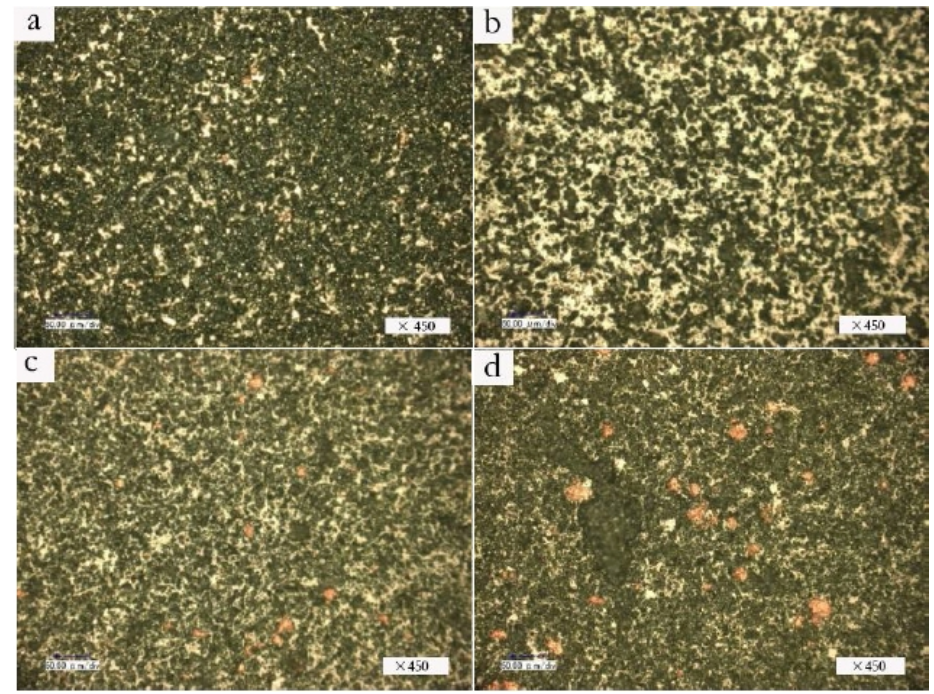

Fig2. Microstructure images of $\mathrm{B}_{4} \mathrm{C}$ samples with different contents of carbon black of $3.5 \mathrm{wt} \%$ (a), $4.5 \mathrm{wt} \%$ (b), $5.5 \mathrm{wt} \%(\mathrm{c})$, and $6.5 \mathrm{wt} \%(\mathrm{~d})$

\section{Phenolic resin to the performance of $\mathrm{B}_{4} \mathrm{C}$}

The raw materials were selected according to the system- 2 of the Table 1 . Phenolic resin was chosen as main sintering aids with the calculated weight of carbide content of $0.5 \%, 1.0 \%, 1.5 \%, 2.0 \%$ and no carbon black were added. The density of boron carbide with varying addition of phenolic resin in the range of $0.5 \%-2.0 \%$ is shown in Fig. 3. The density of $\mathrm{B}_{4} \mathrm{C}$ showed a upward trend as the addition of phenolic resin initially increased, and then went down as the addition of phenolic resin increased further. The density attained its maximum value $2.31 \mathrm{~g} / \mathrm{cm}^{3}$, when the content of phenolic resin was $1.5 \mathrm{wt} \%$.

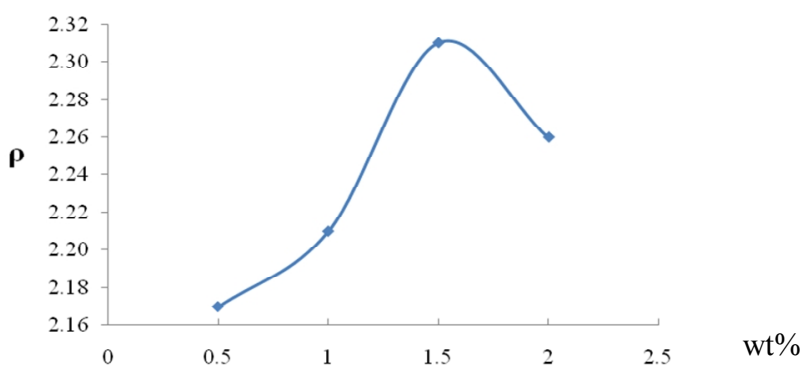

Fig3.the densities of $\mathrm{B}_{4} \mathrm{C}$ samples with different contents of phenolic resins

Microstructures of sintered boron carbide samples with phenolic resins additions are given in Fig.4. Fig. 4( $\mathrm{a}$ and $\mathrm{b})$ present the samples with $0.5 \%$ and $1.0 \%$ phenolic resins with small and uniformly distributed pores. Microstructures of $\mathrm{B}_{4} \mathrm{C}$ with $1.5 \%$ phenolic resins is shown in Fig. $4 \mathrm{c}$, which the number of pores was less but the size of the pores seemed bigger. Fig. $4 \mathrm{~d}$ presents that the sample with $2.0 \%$ phenolic resins with small size but much more pores, and some of which are interconnected. However, the density of the $\mathrm{B}_{4} \mathrm{C}$ showed a certain higher but the porosity of the samples still remained big, which decreased the sintered density. 


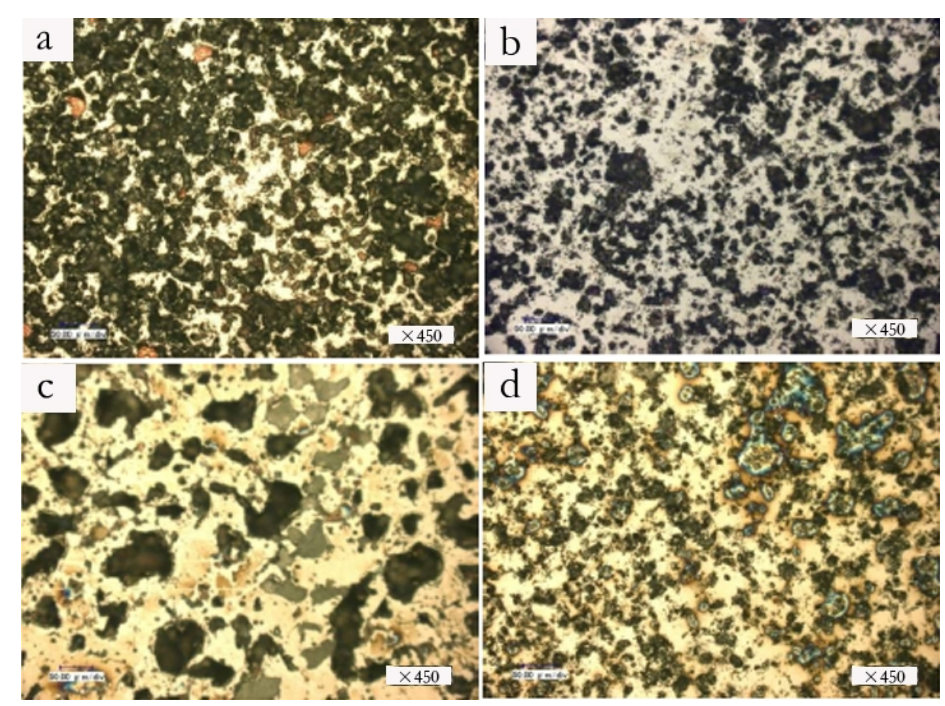

Fig4. Microstructure images of $\mathrm{B}_{4} \mathrm{C}$ samples with different contents of phenolic resins of $0.5 \mathrm{wt} \%$ (a), $1.0 \mathrm{wt} \%$ (b), $1.5 \mathrm{wt} \%$ (c), and $2.0 \mathrm{wt} \%(\mathrm{~d})$.

\section{Adding mixture of carbon and phenolic resin for the performance of $\mathrm{B}_{\mathbf{4}} \mathrm{C}$}

The raw materials were selected according to the system-3 of the Table 1 . The $\mathrm{C}$ source is produced according to the ratio to mixtures of $\mathrm{C}$ black $(3.5 \mathrm{wt} \%, 4.5 \mathrm{wt} \%, 5.5 \mathrm{wt} \%, 6.5 \mathrm{wt} \%)$ plus phenolic resins $(0.5 \mathrm{wt} \%, 1.0 \mathrm{wt} \%, 1.5 \mathrm{wt} \%, 2.0 \mathrm{wt} \%)$, respectively. The density of $\mathrm{B}_{4} \mathrm{C}$ against the mixture of Carbon and phenolic resins in the range of $4.0 \mathrm{wt} \%-8.5 \mathrm{wt} \%$ is shown in Fig. 5. The density of $\mathrm{B}_{4} \mathrm{C}$ showed a upward trend as the $\mathrm{C}$ aids increased, and then changed slightly as the $\mathrm{C}$ aids resin increased further. The density achieved its maximum value $2.41 \mathrm{~g} / \mathrm{cm}^{3}$, when the content of $\mathrm{C}$ aids $(\mathrm{C}$ black $5.5 \mathrm{wt} \%+$ phenolic resins $1.5 \mathrm{wt} \%$ ) was $7.0 \mathrm{wt} \%$.

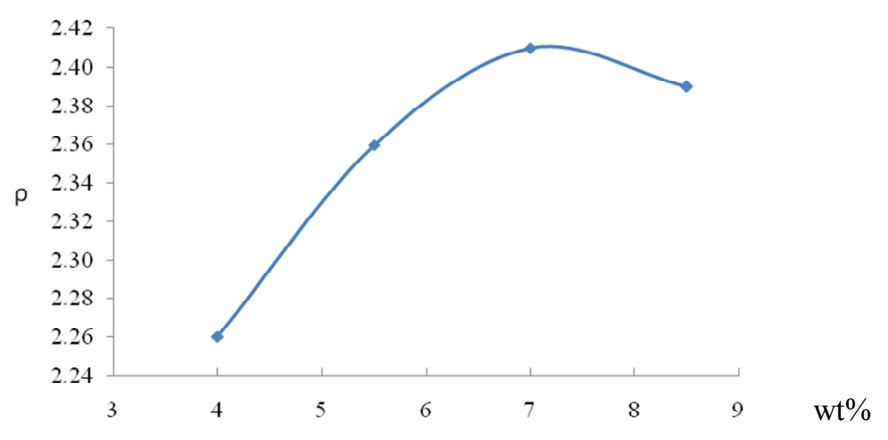

Fig5.the densities of B4C samples with different contents of carbon

Microstructures of sintered boron carbide samples with $\mathrm{C}$ aids $(4.0 \mathrm{wt} \%, 5.5 \mathrm{wt} \%, 7.0 \mathrm{wt} \%, 8.5 \mathrm{wt} \%)$ are given in Fig.6. Fig.6( $\mathrm{a}$ and $\mathrm{b}$ ) present the samples with $4.0 \%$ and $5.5 \% \mathrm{C}$ aids with big and uniformly distributed pores. Microstructures of $\mathrm{B}_{4} \mathrm{C}$ with $7.0 \mathrm{wt} \%(\mathrm{C}$ black $5.5 \mathrm{wt} \%+$ phenolic resins $1.5 \mathrm{wt} \%$ ) is shown in Fig.6c, which both the number is less and the size of pores showed markedly smaller. Fig. $6 \mathrm{~d}$ presents that the sample with $8.5 \mathrm{wt} \% \mathrm{C}$ aids with excessive pores, which could lead the decrease of the densities of the samples. 


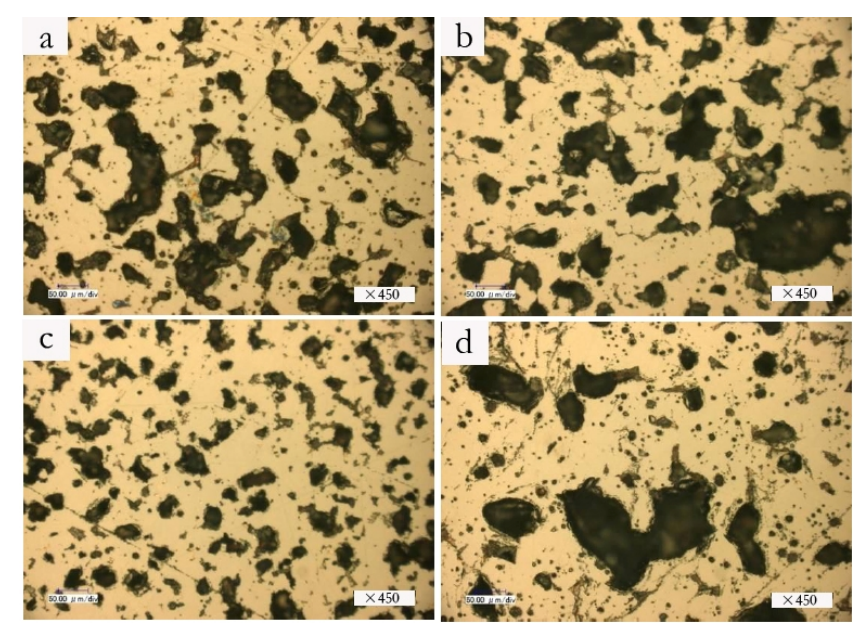

Fig6. Microstructure images of $\mathrm{B}_{4} \mathrm{C}$ samples with different contents of carbon of $4.0 \mathrm{wt} \%$ (a), $5.5 \mathrm{wt} \%$ (b), $7.0 \mathrm{wt} \%$ (c), and $8.5 \mathrm{wt} \%(\mathrm{~d})$.

The impact of mixture of carbon and phenolic resin for the mechanical properties of $\mathrm{B}_{4} \mathrm{C}$

Table 2 presents data on the mechanical properties of pressureless sintered samples with only addition of carbon black of $5.5 \mathrm{wt} \%$; only adding phenolic resin $1.5 \mathrm{wt} \%$; and adding mixture of carbon black $(5.5 \mathrm{wt} \%)$ plus phenolic resin $(1.5 \mathrm{wt} \%)$. The results showed that the bending strength, hardness and fracture toughness are less than $300 \mathrm{Mpa}, 22 \mathrm{Gpa}$ and $3 \mathrm{Mpa} \bullet \mathrm{m}^{1 / 2}$ respectively for the only adding carbon black $(5.5 \mathrm{wt} \%)$ or only adding phenolic resin( $1.5 \mathrm{wt} \%)$. From the table 2 also shows the best $\mathrm{C}$ source is mixtures of $\mathrm{C}$ black $(5.5 \mathrm{wt} \%)$ plus phenolic resins $(1.5 \mathrm{wt} \%)$, the optimum bending strength, hardness and fracture toughness are $335 \mathrm{Mpa}, 22 \mathrm{Gpa}$ and $3.17 \mathrm{Mpa} \cdot \mathrm{m}^{1 / 2}$ respectively.

Table 2 different sintering aids on the mechanical properties of $\mathrm{B}_{4} \mathrm{C}$ ceramics

\begin{tabular}{|c|c|c|c|c|c|}
\hline Sintering aids & number & $\begin{array}{c}\text { Bending } \\
\text { strength } \\
{[\mathrm{MPa}]}\end{array}$ & $\begin{array}{c}\text { hardnessHV } \\
\text { [GPa] }\end{array}$ & $\begin{array}{c}\text { Average } \\
\text { hardness } \\
{[\mathrm{GPa}]}\end{array}$ & $\begin{array}{c}\text { Fracture } \\
\text { toughness } \\
{\left[\mathrm{Mpa} \cdot \mathrm{m}^{1 / 2}\right]}\end{array}$ \\
\hline \multirow{4}{*}{$\begin{array}{c}\text { Carbon black } \\
5.5 \mathrm{wt} \%\end{array}$} & $1-1$ & 292 & 20.64 & \multirow{4}{*}{20.66} & \multirow{4}{*}{2.78} \\
\hline & $1-2$ & 301 & 20.75 & & \\
\hline & $1-3$ & 288 & 20.54 & & \\
\hline & $1-4$ & 295 & 20.69 & & \\
\hline \multirow{4}{*}{$\begin{array}{c}\text { Phenolic resin } \\
1.5 \mathrm{wt} \%\end{array}$} & $2-1$ & 295 & 21.55 & \multirow{4}{*}{21.60} & \multirow{4}{*}{2.93} \\
\hline & $2-2$ & 282 & 21.63 & & \\
\hline & $2-3$ & 261 & 21.60 & & \\
\hline & $2-4$ & 298 & 21.61 & & \\
\hline \multirow{4}{*}{$\begin{array}{c}\text { Carbon } \\
\text { black5.5wt\% } \\
\text { plus phenolic } \\
\text { resin } 1.5 \mathrm{wt} \%\end{array}$} & $3-1$ & 322 & 22.63 & \multirow{4}{*}{22.66} & \multirow{4}{*}{3.17} \\
\hline & $3-2$ & 335 & 22.61 & & \\
\hline & $3-3$ & 311 & 22.71 & & \\
\hline & $3-4$ & 319 & 22.68 & & \\
\hline
\end{tabular}

For only adding Carbon or phenolic resin alone, the best value of bending strength and the fracture toughness of the $\mathrm{B}_{4} \mathrm{C}$ ceramics samples were not as good as adding mixture of Carbon and phenolic resin.

The peak value of bending strength and fracture toughness were reached 335Mpa and 22Gpa with adding mixture of carbon black plus phenolic resin. The results showed that the benefits by adding 
appropriate amount of carbon could be summarized as following; the driving force for the ceramic sintering is the different of surface energy between the powder particle surface and the sintered polycrystalline particles surface; this will cause the decrease of the system free energy[7,8]. Duringthe maunufacture of $\mathrm{B}_{4} \mathrm{C}$ powder, the powder surface will form a very thin oxide layer; this very thin oxide layer will block the materials transfer during sintering, and also the oxide layer will reduve the activity of the powder itself; this will halt the large $\mathrm{B}_{4} \mathrm{C}$ ceramic forming during sintering. By adding suitable amount of Carbon, this can get rid of surface oxide layer in the $\mathrm{B}_{4} \mathrm{C}$ surface; reduce the resistance again the sintering reaction by increasing the surface energy of the $\mathrm{B}_{4} \mathrm{C}$ powde[9]r. This will benefits the formation of the ceramic and increase the ceramic density, the hardness of the ceramic will improve as well. But if adding too much Carbon; there will be some Carbon residual remains after the sintering reaction. This extra free carbon inside the ceramic will lead to more pores and reduce the density of the ceramic as well; this soft Carbon rich area inside the ceramic will certainly results the lower hardness of the ceramic[10].

By adding Carbon; this will lead to the greater bulk diffusion coefficient and removing oxide film from the surface of $\mathrm{B}_{4} \mathrm{C}$ particles. The process of grain migrating and growth could take place of the vacancy caused by survived $\mathrm{B}_{2} \mathrm{O}_{3}$ and free $\mathrm{B}[11]$. This leads to clean grains and boundaries, the crystal grains integrate densely, which could benefit to grain refinement, the porosity and the pore size decreasing, the distribution of pores uniformly. So the $\mathrm{B}_{4} \mathrm{C}$ ceramics has compact structure, and its hardness, bending strength and fracture toughness are all increased.

\section{Summary}

The optimized properties of the sintered $\mathrm{B}_{4} \mathrm{C}$ are not achieved by adding Carbon or phenolic resin alone.

By adding certain mixtures of Carbon and phenolic resin, the optimized higher density of sintered $\mathrm{B}_{4} \mathrm{C}$ was obtained. Firstly the phenolic resin worked as an adhesive agent to adhere $\mathrm{B}_{4} \mathrm{C}$ particles, secondly the phenolic resin distributed uniformly along the grain boundaries or in the grain interiors after decompose to tiny carbon grains, which could increase the surface energy and sintering activity of powders, could decrease the surface diffusion and evaporation of the carbon, and control grain boundary motion.

For the compound compositions of our pressureless sintering $\mathrm{B}_{4} \mathrm{C}$ ceramics, the best solid sintering aids is the adding the mixture of carbon black and phenolic resins-carbon black $5.5 \%$ and the phenolic resins $1.5 \%$. The optimum bulk density, bending strength, hardness and fracture toughness are $2.42 \mathrm{~g} / \mathrm{cm}^{3}, 335 \mathrm{MPa}, 22 \mathrm{Gpa}$ and $3.17 \mathrm{MPa} \cdot \mathrm{m}^{1 / 2}$ respectively under that conditions.

\section{References}

[1] C. Subramanian, T.K. Roy b, T.S.R.Ch.Murthy, et al., Effect of zirconia addition on pressureless sintering of boron carbide, J. Ceramics International 34 (2008) 1543-1549.

[2] Matan Cafri, Alon Malka, Helen Dilman, Moshe P. Dariel, and Nahum Frage, Reaction-bonded boron carbide/magnesium-silicon composites, Int. J. Appl. Ceram. Technol., 11[2] 273-279

[3] S. Hayun, H. Dilman, M. P. Dariel, N. Frage, and S. Dub, The effect of carbon source on the microstructure and the mechanical properties of reaction bonded boron carbide, Advances in Sintering Science and Technology: Ceramic Transactions, (eds.), R. K. Bordia and E. A. Olevsky, JohnWiley \& Sons, Inc., Hoboken, NJ, 2010:29-39.

[4] Baichun Mu,Lidan Tang,Hui Zhang, Influence of the sintered catalyst on the properties of boron carbide, J. China Ceramics1001-9642(2007)12-16 in chinese.

[5] R.F. Speyer, H. Lee, Advances in pressureless densification of boron carbide, J. Mater. Sci., 39 (2004) 6017-6021. 
[6] Bangyao Yin, Lingsen Wang, Yancu Fang, Sintering mechanism of pure and carbon-doped boron carbide, J. J. Chin. Ceram. Soc., 29 (2001) 68-73 in chinese.

[7] Schwetz K A et al.,U.S. Patent 4,195,066. (1980)

[8] Lingsen Wang, Yibing Yang, Jingsheng Zhang, Yi Fan and Fang Wu, Study on the mechanism and kenetic of boron carbide sintering, J. J.Cent. South Univ. Technol., 30(1995)505-508 in chinese.

[9]] S. Hayun, A. Weizmann, M. P. Dariel, and N. Frage, Microstructural evolution during the infiltration of boron carbide with molten silicon,J. Eur. Ceram. Soc., 30 (2010) 1007-1014..

[10] Prochazka S, Dole S L, k Hejna CI, Abnormal grain growth and microcracking in boron carbide, J. J. Am. Cream Soc.,68 (1985) 235-236.

[11] Liangji Shen, Wenxin Li, Li Zhang, Study on boron carbide ceramics sintering method,J. Journal of Harbin University of Commerce (Natural Sciences Edition),26(2010)608-610 in chinese. 